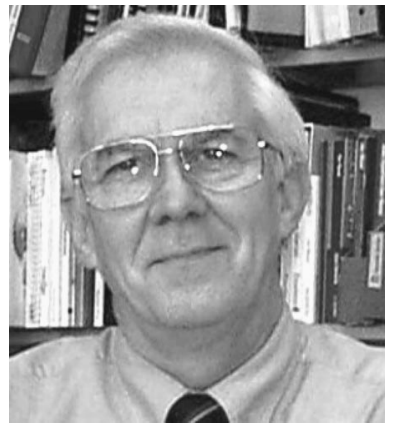

\section{The Claw}

One of the delights of doing graduate work at Johns Hopkins back in the sixties was that I got to play with some of the old optical instruments that had been acquired over time. Most of them, probably ordered by Henry Rowland, were made in Germany, before the turn of the century. All were brass and steel and beautiful to behold. But just as useful and, in its own special way, just as beautiful is an opto-mechanical device that has a number of names, but I call it "the claw."

The first optical mounts and benches that I used were those ugly and ungainly black Cenco benches. We still have a few in the optics lab upstairs. It wasn't until I got to Hopkins that I saw the big optical tables with vibration isolation. My own laser Raman spectroscopy work was done on a standard lab table. For me, the real innovation was the triangular Zeiss profile rails with cross-feed and vertical motion. Adjustments were easy and for the experiments of the time, the system worked well.

My first optical table with vibration isolation was not one made by Newport or TMC, but rather a surplused mechanical layout table from NASA Huntsville. For vibration isolation, I found isolators made by Firestone out of a small tire attached to two plates. Normally they had been used for load isolation on trucks, and the weight of the layout table was as much as a small-size truck. I've always counted myself lucky that I was out of town when the riggers installed the table since, I was later told, it was a struggle to get it in the lab and located. Atop the table I plunked my laser, spectrometer, and the optics for light scattering experiments-again using Zeiss profile optics along with some new modular Spindler \& Hoyer microbench components.

But the era of linear optical systems was coming to an end. With the advent of holography, beams had to come in from odd angles and, in some cases, different heights. One solution that we used in our holography laboratory was an optical bench by Gaertner. It consisted of a set of nine slightly raised rails parallel to one another and carriers with magnetic hold-downs. These provided needed flexibility to position optical components inside a volume. But this system had severe drawbacks. The components were large, and a simple experiment took up a lot of real estate in the lab.

I disappeared from the lab for awhile. I wrote a book, did some work in opto-mechanical design, and assembled an educational optics kit. When I returned to laboratory research and began to work on diffractive optics, I promptly assembled a scatterometer on an optical breadboard, still using Zeiss profile rails on the breadboard. My colleagues, however, rarely used these rails. Their approach was to use the entire space of the optical table. They mounted component holders directly onto the table, in some cases attaching them with quick-setting epoxy. It certainly gave you freedom, but it made adjustments more difficult. You had to whack the holder with a blunt object, dissolve the solid epoxy, and reset the holder.

Beside the scatterometer, the work on diffractive optics required only a simple reduction camera and a lens bench. When the work in diffractive optics had finished, I switched to doing ultrafast optics with Rick Trebino and my son, as I described in a previous editorial ("My Research Colleague," October 2001). After designing my system, I went into Rick's lab to prototype the new device. There was not a triangular rail to be seen. The drawers were stocked with mounts, posts, post holders, and a wide selection of mirrors, lenses, and prisms. Rick's lab is an experimenter's dream. It was then that I first encountered the claw.

I knew that it existed. I had seen this little device in most optics labs over the past few years, but I did not appreciate how useful it could be. I started on a small breadboard atop one of the large optical tables in the lab and proceeded to locate the components on posts within adjustable post holders. Each of the post holders has a flanged washer screwed into the bottom so that they can stand stably by themselves. But to locate it you take this claw...prong...fork? The manufacturer, New Focus, calls it a Holding Fork. It is a two-tined device with a slot in the "handle" of the fork. In that slot is a captive 1/4-20 Allen screw that when screwed into the optical table holds the fork and the post holder firmly to the table. What this means is that you can put a component anywhere you want on the table. ANYWHERE! Once you locate the screw in a hole in the table, the claw can be moved over a wide area and thus components can easily be positioned 


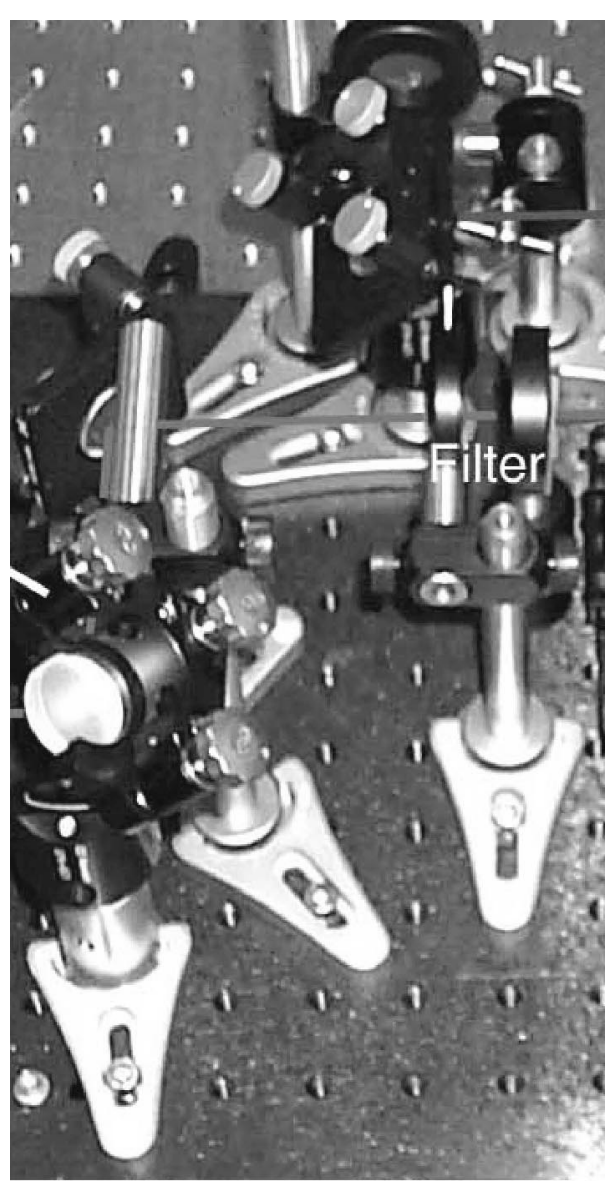

Fig. 1 Five claws at work. in an optimum geometry. Figure 1 shows five claws at work.

So, what's the big deal? Before the claw, when I was assembling a device or establishing a new experiment, there was invariably some component or bracket that had to be made by the shop before I could continue. This slowed the work and reduced my momentum, not to mention the dialogs with the shop. Now, with the claw and a little ingenuity, I can make almost anything I want and get it working the same day. The components can be located in proximity to each other, and because of the ease with which you can move or adjust them a design can be revised and evaluated quickly. In the space of a few days a system can be built, evaluated, and optimized. 'Tis bliss!

Where did this little gadget come from? I found out from Milton Chang, one of the founders of New Focus, that Frank Luecke, a fellow cofounder, designed the claw. According to Milton, Luecke advocated that designers emphasize "form over function." Although the claw is a somewhat ungainly looking device, Milton noted that "... a lot of the products he designed are aesthetically pleasing."

There must be many graduate students and researchers in optics and photonics who owe a piece of their sanity to Mr. Luecke. I count myself among them.

Donald C. O'Shea Editor 